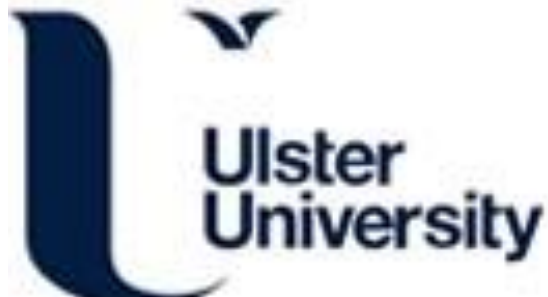

\section{Numerical investigation of externally venting flame characteristics in a corridor-façade configuration}

Asimakopoulou, E. K., Chotzoglou, K. E., Kolaitis, D., Zhang, J., \& Delichatsios, M. A. (2019). Numerical investigation of externally venting flame characteristics in a corridor-façade configuration. Fire Safety Journal, 110, [102912]. https://doi.org/10.1016/j.firesaf.2019.102912, https://doi.org/10.1016/j.firesaf.2019.102912

Link to publication record in Ulster University Research Portal

\section{Published in:}

Fire Safety Journal

Publication Status:

Published (in print/issue): 01/12/2019

DOI:

10.1016/j.firesaf.2019.102912

10.1016/j.firesaf.2019.102912

\section{Document Version}

Author Accepted version

\section{General rights}

Copyright for the publications made accessible via Ulster University's Research Portal is retained by the author(s) and / or other copyright owners and it is a condition of accessing these publications that users recognise and abide by the legal requirements associated with these rights.

\section{Take down policy}

The Research Portal is Ulster University's institutional repository that provides access to Ulster's research outputs. Every effort has been made to ensure that content in the Research Portal does not infringe any person's rights, or applicable UK laws. If you discover content in the Research Portal that you believe breaches copyright or violates any law, please contact pure-support@ulster.ac.uk. 


\section{Journal Pre-proof}

\section{FIRE}

Numerical investigation of externally venting flame characteristics in a corridor-façade configuration

Eleni K. Asimakopoulou, Konstantinos E. Chotzoglou, Dionysios Kolaitis, Jianping Zhang, Michael A. Delichatsios

PII:

S0379-7112(19)30384-4

DOI: https://doi.org/10.1016/j.firesaf.2019.102912

Reference:

FISJ 102912

To appear in: Fire Safety Journal

Received Date: 22 July 2019

Revised Date: 9 October 2019

Accepted Date: 5 November 2019

Please cite this article as: E.K. Asimakopoulou, K.E. Chotzoglou, D. Kolaitis, J. Zhang, M.A. Delichatsios, Numerical investigation of externally venting flame characteristics in a corridor-façade configuration, Fire Safety Journal (2019), doi: https://doi.org/10.1016/j.firesaf.2019.102912.

This is a PDF file of an article that has undergone enhancements after acceptance, such as the addition of a cover page and metadata, and formatting for readability, but it is not yet the definitive version of record. This version will undergo additional copyediting, typesetting and review before it is published in its final form, but we are providing this version to give early visibility of the article. Please note that, during the production process, errors may be discovered which could affect the content, and all legal disclaimers that apply to the journal pertain.

(C) 2019 Published by Elsevier Ltd. 


\title{
Numerical investigation of externally venting flame characteristics in a corridor-like configuration
}

\author{
Eleni K. ASIMAKOPOULOU ${ }^{1}$, Konstantinos E. CHOTZOGLOU ${ }^{1,2}$, Dionysios KOLAITIS ${ }^{3}$, Jianping ZHANG ${ }^{1}$ \\ and Michael A. DELICHATSIOS ${ }^{4,5}$ \\ ${ }^{1}$ FireSERT, Belfast School of Architecture and the Built Environment, Ulster University, \\ Newtownabbey BT37 OQB, United Kingdom \\ ${ }^{2}$ Efectis United Kingdom/Ireland \\ ${ }^{3}$ Laboratory of Heterogeneous Mixtures and Combustion Systems, School of Mechanical Engineering, National \\ Technical University of Athens, 9 Heroon Polytechneiou St., Polytechneioupoli Zografou, Athens 15780, Greece \\ ${ }^{4}$ Northeastern University, Boston, USA \\ ${ }^{5}$ University of Science and Technology of China (USTC), Hefei, China
}

Corresponding author info: e.asimakopoulou@ulster.ac.uk, telephone number: +44(0)2890368245, fax number: $+44(0) 1232368700$

ORCID: 0000-0001-5644-1372

\section{ACKNOWLEDGEMENTS}

This work is conducted and financially supported within the frame of "ELISSA: Energy Efficient Lightweight-Sustainable-Safe-Steel Construction” FP7 project (FP7-2013-NMP-ENV-EeB, Grant No. 609086). Technical assistance of Mr. M. McKee, Mr. B. Veighy, W. Allison and Mr. K. Kowalski is gratefully acknowledged. 


\title{
Numerical investigation of externally venting flame characteristics in a
}

\section{corridor-façade configuration}

\begin{abstract}
This study investigates numerically the burning behaviour of a liquid pool fire in a medium-scale corridor-like enclosure in order to identify the key factors influencing External Venting Flames (EVF) characteristics as well as heat impact of the EVF on façades. Simulations were performed for four doorlike openings with the fire located either at the front or back of the enclosure and the predicted gas temperatures and heat fluxes are analysed and compared with experimental data. Results show that FDS generally predicts accurately the gas temperature inside the corridor and captures well the detachment and propagation of the flame when the burner is positioned at the back of the corridor. The heat fluxes on the floor of the corridor are reasonably predicted in terms of both trends and maximum values for the cases where the fire is located at the back of corridor but generally under-predicted for the test cases where the burner is located at the front. Though similar trends, the predicted heat fluxes on the façade are considerably lower than the measurements highlighting the importance of accurate prediction of the burning characteristics of the EVF on the heat impact on the facade.
\end{abstract}

KEYWORDS: corridor-façade fire; externally venting flames; computational fluid dynamics (CFD); fire dynamics simulator (FDS) 


\section{INTRODUCTION}

Understanding the characteristics of compartment fire development and Externally Venting Flames (EVF) is fundamental for studying fire spread in high-rise buildings or to adjacent structures. Despite significant effort devoted to studying the fire development in cubic-like enclosures, limited data exist for more complex geometries that are commonly used in modern constructions including corridor-like enclosures. The mechanism of fire spreading in corridor-like enclosures is significantly different from that in cubic-like enclosures as the fire plume impinges on the ceiling resulting in thermal stratification, generation of smoke and toxic gases that are difficult to exhaust due to geometric confinements. Studies $[1,2,3,4,5]$ have highlighted the urgent needs for further investigation on the physics of fire growth in corridor-like enclosures and the fundamental mechanisms that may eventually lead to external fire spread.

In a previous experimental work [4], the authors have shown that, for a liquid pool fire located in a corridor-like enclosure, three burning regions can be observed (Region I, II and III), corresponding respectively to fuel-controlled, ventilation-controlled and steady-state burning after flame ejection and that the occurrence of Regions II and III and the duration of each region depends on both the pan size and ventilation factor. The fire grows as fuel-controlled in Region I and then becomes ventilationcontrolled in Region II where the heat release rate (HRR) reaches a plateau, i.e., the maximum HRR inside the enclosure controlled by the ventilation factor. Flames ejection, as observed visually and through image processing, is associated with a sudden increase of the HRR, indicating the beginning of Region III, where sustained external burning is observed until a further plateau is formed near the end of the test indicating that steady state conditions are established. It was also observed in [4] that the 
maximum HRR inside the enclosure does not reach the maximum value commonly used for rectangular compartments, i.e., $1500 A_{o} H_{o}{ }^{1 / 2}$ [6]. The corresponding value the corridor-like enclosure was found to be $1110 A_{o} H_{o}{ }^{1 / 2}$, indicating that the amount of air inflow in long corridors is less than that in rectangular enclosures with the same opening dimensions [7]. For the cases where ventilation-controlled conditions are achieved, the normalized steady state mass burning rate is found to increases linearly with the normalized ventilation factor which is consistent with previous findings with cubic-like enclosures. The location and size of the fuel pan was also found to have a strong impact on HRR and subsequent EVF characteristics $[4,5]$.

As the Fire Dynamics Simulator (FDS) is used as the numerical tool in this work, it is useful to include here a brief review on recent numerical studies of medium-scale enclosure fires employing FDS as summarised in Table 1. It has been reported that turbulence parameters, $C_{s}$ and $S_{c}$, do not directly affect HRR predictions $[8,9]$ but there are indications that $P_{r}$ may influence mean compartment temperatures [9]. Though numerous investigations have been conducted using CFD-based techniques to simulate fire development in compartment-façade configurations [e.g., 10, 11, 12, 13, 14, 15] there are limited studies specifically focusing on the development and characterization of the resulting EVF in medium-scale configurations and relevant façade fire safety issues [16, 17, 18, 19, 20,21]. FDS predictive accuracy of the upper layer gas temperatures in enclosures $[8,9,16]$ was found to be limited, the main drawback being the insufficient representation of combustion inefficiency during under-ventilated fires [8, 16]. Despite the above-mentioned limitations, it was noted in $[11,17,23]$ that FDS may adequately be used for a qualitative assessment of the parameters that may influence the medium-scale enclosure fire development. 
Currently, there are no specific methodologies to evaluate risks associated with EVF in "performancebased" fire safety codes and only few numerical simulation studies have been carried out on the burning characteristics of EVF in corridors and relevant façade fire safety issues. To close this knowledge gap, this study is aimed at investigating numerically the burning behaviour of liquid fuel pool fires in corridor-like geometries in order to identify the key factors influencing EVF characteristics and their impact on the façade. Fire Dynamics Simulator (FDS) version 6.7.1 was used and the simulation results are compared and validated against experimental data obtained in [4]. A wealth of information regarding the detailed characteristics of the thermal-field developing inside or outside the compartment are provided and as a result, the thermal impact of EVF on the façade elements can be assessed. A parametric study has also been performed to further investigate the effects of ventilation and location of the burner.

\section{EXPERIMENTAL SETUP AND NUMERICAL DETAILS}

\subsection{Experimental setup}

The detailed experimental setup can be found in [4]. Figure 1 shows a schematic view of the experimental set-up along with the experimental measurement locations, consisting of temperatures inside the corridor, heat fluxes on the floor of the corridor enclosure and on the façade, heat release rate and mass loss rate. Stainless steel sheath type K bare-bead thermocouples with a diameter of $1.5 \mathrm{~mm}$ were used for temperature measurements. A detailed uncertainty analysis of the experimental apparatus can be found in [4]. The effect of ventilation was investigated by altering the dimensions of the opening. Four different door-like openings were used, with their dimensions shown in Table 2. A stainless-steel circular pan, $6 \mathrm{~cm}$ high and $30 \mathrm{~cm}$ in diameter was used. A water-cooling circuit wrapped around the 
pan helps retain constant pan temperature to reduce conductive heat losses and thus retain constant burning rates. The pan was placed at the center in either Box A or Box F. A level maintenance system was used to keep a constant fuel level $(10 \mathrm{~mm}$ from the pan's rim) to minimize lip effects and to establish steady-state conditions within the enclosure. In order to measure the mass loss rate of ethanol during burning, the upper and lower tanks of the fuel supply and level maintenance system were placed on a balance, which has a maximum load of $36 \mathrm{~kg}$ with $0.2 \mathrm{~g}$ accuracy. The mass was logged and recorded every $3 \mathrm{~s}$.

A summary of the main operational parameters i.e., burner position, opening height $\left(H_{o}\right)$, opening width $\left(W_{o}\right)$, total fire duration $\left(t_{d u r}\right)$, time of EVF ejection from the opening $\left(t_{E V F}\right)$, total HRR experimentally measured $\left(Q_{\text {exp }}\right)$, theoretical HRR $\left(Q_{t h}\right)$ and ventilation regime (Under- or Over-ventilated, indicated as $\mathrm{U}$ or $\mathrm{O}$ respectively) is also presented in Table 2 for each test case. To establish a relationship between ventilation conditions and the fuel mass loss rate, the theoretical global equivalence ratio (GER) was estimated using Equation 1 [24], where $r_{o}$ is the oxygen to fuel stoichiometric ratio, valued 9 for ethanol, and $Y_{O 2, \text { air }}$ is the mass fraction of oxygen in air (0.23). When the value of GER exceeds unity, the fire is considered as ventilation-controlled (under-ventilated); when GER is less than one, the fire is regarded as fuel-controlled (well ventilated). $Q_{t h}$, is calculated by multiplying the measured fuel mass loss rate (MLR) by the heat of combustion of ethanol, $26.78 \mathrm{MJ} / \mathrm{kg}$ [24]. It should be noted that the maximum HRR inside the corridor-enclosure at stoichiometric conditions in the current work is calculated as $1110 A_{o} H_{o}^{1 / 2}$ based on the experimental finding in [4].

$$
G E R=\frac{\dot{Q}_{t h}}{\dot{Q}_{s t, i n}}=\frac{\dot{m}_{T} \cdot r_{o}}{\dot{m}_{a} \cdot Y_{O_{2, a i r}}}=\frac{\dot{m}_{T} \Delta H_{c}}{1110 A_{o} H_{o}{ }^{1 / 2}}
$$


The experimental HRRs in [4] were used as the inputs of the simulations. Figure 2 presents the temporal evolution of the HRR $\left(Q_{\text {exp }}\right)$ as well as that of $\mathrm{CO}$ concentration for all the cases. As the ventilation factor, $A_{o} H_{o}{ }^{1 / 2}$, increases, $Q_{\text {exp }}$ increases. The flame ejection time, $t_{E V F}$, is also indicated in Figure 2 . It is important to note that for the cases where the fire is located at the front box (i.e., near the opening), the flame ejects very early due to the fact that the HRR is large in relation to the height of the enclosure and the flames are long along the ceiling of the enclosure, and therefore $t_{E V F}$ cannot be used as indication of transition from under-ventilated conditions to external burning. In the FR30W50H50 case with large opening dimensions, no steady-state conditions were reached after 40 minutes. The experiment had to be terminated for not damaging the experimental rig. Instead of the steady-state values, the final values of the result profiles before the end of the experiment were used in the analysis although those values are expected to further increase.

In comparison, for the cases where the fire is located at the back of the enclosure, the three regions can be clearly observed. Flame ejection is associated with a sudden increase in the $Q_{\text {exp }}$ at the beginning of Region III, where sustained external burning is observed until a plateau is formed indicating that steady state conditions are established. The start of Region II corresponds to a transition from fuel- to ventilation-controlled conditions where combustion efficiency is decreased due to insufficient $\mathrm{O}_{2}$ availability thus resulting in a significantly increased production of CO. During Region III, the CO concentration is decreased due to external burning.

\subsection{Numerical details}


In the general context of compartment fire simulations, the quality of the utilized grid resolution is commonly assessed using the non-dimensional $D^{*} / \delta x$ ratio, where $D^{*}$ is a characteristic fire diameter and $\delta x$ is the nominal size of the grid cell. The $D^{*} / \delta x$ ratio corresponds to the number of computational cells spanning $D^{*}$ and is representative of the adequacy of the grid resolution. If the value of the $D^{* / \delta x}$ ratio is sufficiently large, the fire can be considered well resolved. Several studies have shown that values of 10 or more are required to adequately resolve most fires and obtain reliable flame temperatures [7, 25]. In the current study, a $0.02 \mathrm{~m}$ cell size is used based on grid sensitivity study. As the maximum HRR in different tests ranges from 34 to $100 \mathrm{~kW}$, the value of $\mathrm{D} * / \delta \mathrm{x}$ calculated varies from 12 to 19 , indicating that the fire is adequately resolved [26]. The numerical domain extends to the outside of the enclosure in order to effectively simulate air entrainment through the opening and burning outside the compartment. The size of the physical domain "extensions", $1.0 \mathrm{~m}$ in the $\mathrm{x}$ - and $1.5 \mathrm{~m}$ in the z-direction, have been selected following findings in a relevant study on the effect of computational domain size on numerical simulation of compartment fire [27]. The outer dimensions of the simulation domain are depicted in Figure 3 and the computational grid consists of 375,000 cubic cells.

The experimental HRR, $Q_{\text {exp }}$, in Figure 2 was used as an input in the form of Heat Release Rate Per Unit Area (HRRPUA) in the upper surface of the pool in the FDS simulations. The pool fire was approximated as a rectangle having the same surface area to the circular pan used in the experiments.

In FDS [26], the core algorithm is an explicit predictor-corrector scheme that is second order accurate in space and time. Turbulence is treated using the Very Large Eddy Simulation (VLES) approach. A transport algorithm for the density and species mass fraction was introduced, namely the Total Variation Diminishing transport algorithm. A filtration procedure is employed using the characteristic grid cell 
length as the filter width. Averaging is only performed for turbulent fluctuations exhibiting length scales smaller than the filter width and a subgrid turbulence model is used for the small-scale turbulent viscosity. In the current simulations, the subgrid scale turbulence is simulated using the Constant Coefficient Smagorinsky eddy viscosity subgrid closure model utilizing a Smagorinsky constant value, $C_{s}$, of 0.2. Concerning turbulence modelling, both turbulent $S_{c}$ and $P_{r}$ values were chosen to be equal to 0.5 based on the finding in [8] for strong buoyant flows originating from enclosure fires occurring inside compartments [8]. The Van Driest modification of the near wall turbulence model is used to calculate the Reynold stresses near wall elements. The time step is dynamically adjusted in order to satisfy the Courant-Friedrich-Levy (CFL) criterion, Equation (2) [26, 28]. The exact CFL value needed to maintain stability depends on the order of the time integration scheme and the choice of the velocity norm. For VLES turbulent model used in the current study, this velocity norm is calculated according to Equation (3), where $\Delta$ is one cell width and $\delta t$ is one-time step.

$$
\begin{aligned}
& C F L=\delta t \frac{\|u\|}{\Delta}<1 \\
& \frac{\|u\|}{\Delta}=\max \left(\frac{|u|}{\delta \mathrm{x}}, \frac{|v|}{\delta v}, \frac{|w|}{\delta z}\right)+|\nabla \cdot \boldsymbol{u}|
\end{aligned}
$$

All solid surfaces are assigned thermal boundary conditions with appropriate material properties. The walls of each test rig, including the corridor and façade wall, consisted of fiberboard with the following properties: $0.02 \mathrm{~m}$ thickness, $300 \mathrm{~kg} / \mathrm{m}^{3}$ density and 0.9 emissivity. Thermal conductivity and heat capacity temperature-dependent values according to the manufacturer as depicted in Figure 4. The soot yield, which represents the fraction of ethanol fuel mass converted to smoke particulates, is set equal to 
$0.8 \%$ and the corresponding $\mathrm{CO}$ yield was set equal to $0.1 \%$, according to available measurements for ethanol [24]. The entire computational domain (both indoors and outdoors) is assumed to be initially still (zero velocity), exhibiting a temperature of $20^{\circ} \mathrm{C}$. For the radiative transport equation, 104 control angles are used, whereas time and angle increments are 3 and 5 respectively. Concerning the radiation solver, it is assumed that the gas behaves as a grey medium with a $0.125 \mathrm{~m}$ path-length $\mathrm{L}$ for RADCAL calculations. The total simulation time is set as the duration of each test case, c.f. Table 1. Open boundaries are imposed at all boundaries external to the enclosure and wall boundary conditions are used for walls, ceiling and floor. Numerical results of the temporal evolution of gas temperatures, and heat fluxes on the floor of the corridor and on the façade are compared to available experimental data [4].

\section{RESULTS AND DISCUSSIONS}

\subsection{Effect of fire position}

Figures 5 and 7 present the spatial distribution of the instantaneous gas temperature (at 60, 120, 400 and 900 s) inside the corridor for the two characteristic test cases BC30W30H30 and FR30W30H30. During Region I, corresponding to $60 \mathrm{~s}$ from fire initiation, low gas temperatures are observed in the lower layer as fresh air enters the enclosure through the opening, located at the far-right side of the corridor. In both cases, FDS accurately predicts the spatial distribution and the entrainment of fresh air to the corridor. In test case BC30W30H30, during Region II, where $400 \mathrm{~s}$ was chosen as an indicative time instance, the highest temperatures are observed at the vicinity of Boxes E and D indicating that combustion mainly takes place at these locations and flames gradually propagate towards the opening seeking available oxygen $[4,29]$. FDS results, though able to depict the gas temperature vertical stratification, do not 
accurately reproduce the combustion zone; for instance, as in the numerical simulation of the $\mathrm{BC} 30 \mathrm{H} 30 \mathrm{~W} 30$ test case the fire plume is mainly located at the back of the corridor, at Box F, near the vicinity of the burner. This results in higher temperatures developed and stronger recirculation zone formed. During Region III, the difference of gas temperatures between the upper and lower layers decreases towards the closed end (far left) of the corridor, but still, they cannot be assumed uniform inside the corridor. In Region III, at 900 s, flames fill the upper layer of the corridor extending towards the opening and eventually emerge from the opening when the HRR becomes sufficiently large. FDS captures well the phenomenon that the flame detaches from the burner after external burning was observed as depicted in the FDS spatial temperature distribution, though higher temperatures are observed.

In order to further investigate the occurrence of each phase in relation to ventilation factor and fire location, Figure 6 shows a comparison of the experimental total HRR $\left(Q_{\text {exp }}\right)$, predicted total HRR $\left(Q_{\text {num,total }}\right)$, the predicted HRR inside the corridor $\left(Q_{\text {num,in }}\right)$ and outside $\left(Q_{\text {num,out }}\right)$ for test case BC30H30W30. Both, $1500 A_{o} H_{o}^{1 / 2}$ and $1110 A_{o} H_{o}{ }^{1 / 2}$ are plotted for immediate comparison with $Q_{\text {num,in }}$. The predicted total HRR agrees well with the experimental one as expected. FDS does predict earlier flame ejection (based on $Q_{\text {num,out }}$ and visual examination of the simulation results) in comparison to the experimental observation. However, a very important finding in Figure 6 is that the HRR inside the corridor equals $1110 A_{o} H_{o}{ }^{1 / 2}$ even after EVF emerge through the opening. This result further confirms the experimental finding in [4] that the amount of air inflow in long corridors is less than that in rectangular enclosures with the same opening dimensions. 
For the FR30W30H30 test case (Figure 6 and Figure 8), temperature stratification in the interior of the corridor is less evident, since EVF emerge more quickly from the opening resulting in lower temperatures in Boxes $\mathrm{C}$ to $\mathrm{F}$. Overall, predictions of gas temperature inside the corridor show good levels of qualitative agreement with the measured values. The CFD model also accurately predicts the presence of the fire plume at the vicinity of Box A, resulting in the emergence of EVF outside the corridor. EVF emerge almost immediately after ignition and the predicted heat release rate inside the corridor $\left(Q_{\text {num,in }}\right)$ never reaches the threshold value $1110 A_{o} H_{o}{ }^{1 / 2}$ indicating that the fire is always overventilated and the external burning occurs due to the fact mentioned earlier that the HRR is large in relation to the height of the enclosure and the flames are long along the ceiling of the enclosure.

Figure 9 and 10 show a comparison of the average experimental and numerical heat fluxes plotted against the distance from the opening for test cases with the fuel pan positioned at the front and the back of the corridor respectively. For the test cases where the burner is located at the back of the corridor, Figure 10, FDS predicts well the trends and maximum values of the heat flux. The peak experimental heat flux values are found at Box D, whereas the numerical ones are at Boxes B or C, indicating that the main combustion zone predicted is located closer to the opening as also confirmed in the temperature results in Figure 5. For the test cases where the burner is located at the front of the corridor, Figure 9, the heat fluxes are generally under-predicted. The predicted peak heat flux values are not located in Box B as recorded in the experiments for all cases. For the cases with $0.5 \mathrm{~m}$ opening width (FR30W5025 and FR30W50H50) the predicted heat flux is considerably different from the experimental one and the peak heat flux is predicted in Boxes $\mathrm{E}$ or $\mathrm{D}$ indicating the formation of a recirculation zone. 
Temporal evolution of the heat fluxes on the façade are illustrated in Figures 11 and 12 for BC30W30H30 and FR30W30H30 respectively. In total, twenty-seven steel plate meters were installed on the façade of the enclosure as shown Figure 1. The steel plate meters have spot-welded thermocouples on the unexposed to fire surface and are embedded into insulation boards [4]. The heat fluxes, using the temperature measurements, are then deduced by solving the three-dimensional conduction equation for both the steel plate and the insulation [30]. Two Gardon gauges (P9 and P13) were also used to check the accuracy of the measurements by the steel plate meters.

For the BC30W30H30 case, the measured heat fluxes on the façade are relatively low because most of combustion occurs inside the corridor resulting in much higher heat fluxes on the corridor floor as shown in Figure 10. The maximum experimental heat flux on the façade occurs at the vicinity of the opening, i.e., positions P1, P2, P3 and P4, as also predicted by FDS. Although FDS predicts relatively well the heat fluxes inside the corridor as well as the general trends of the heat fluxes on the facade, it under-predicts significantly the heat flux on the facade, likely due to the under-prediction of external burning. It is worth noting that both Gardon gauge meters and steel plate meters (P8 and P9 in Figure 10) exhibit similar values verifying the accuracy of the steel plate heat flux metres. Furthermore, heat fluxes at P7 (10 cm to the right of the centreline) and P5 (10 cm to the left of the centreline) are almost identical confirming that the external flames are symmetrical as expected. The results of other cases with the fire located at the back of the corridor have similar trends and are thus not shown here for brevity.

For the FR30W30H30 test case in Figure 12, where the fuel pan is located close to the opening and EVF almost instantly eject through the opening, exposing the façade to significantly increased heat fluxes. FDS predicts well the sudden increase of heat fluxes at around 500s when the HRR reaches it its 
maximum steady value. The predicted heat fluxes are higher than those predicted for BC30W30H30 but still considerably less than the measurements. The large discrepancies in both cases indicate that, in addition to possible under-prediction of external burning, the burning characteristics of the EVF (such as shape and temperature) may also not be correctly predicted by the model. This is certainly worth further investigation both numerically and experimentally through more detailed measurements of the EVF.

\subsection{Effect of ventilation factor}

Figure 13 illustrates the temporal evolution of the measured and predicted upper layer gas temperatures at a height of $48 \mathrm{~cm}$ in Boxes $\mathrm{A}, \mathrm{C}$ and $\mathrm{E}$ for all test cases. In order to quantify the predictive capability of the numerical model and to facilitate comparison between those time-dependent quantities, the metrics $\varepsilon_{1}$ and $\varepsilon_{2}$, as defined and used for fire simulations by Audouin et al. [31] and the ASTM E135597 standard guide [32], are calculated according to Equations (3) and (4), where $\mathrm{x}$ and y represent experimental and numerical values. Results of the respective functional analysis used to compare the time-dependent values for the upper layer temperatures for Boxes A and E are presented in Table 3. The lowest values for the projection coefficient $\varepsilon_{1}$ and the highest for the inner product cosine $\varepsilon_{2}$ are highlighted in Table 3 to assist the interpretation of the results.

$$
\varepsilon_{1}=\frac{\|\bar{y}-\bar{x}\|}{\|\bar{x}\|}=\sqrt{\frac{\sum_{i=1}^{n}\left(y_{i}-x_{i}\right)^{2}}{\sum_{i=1}^{n}\left(x_{i}\right)^{2}}},
$$




$$
\varepsilon_{2}=\cos (\bar{x}, \bar{y})=\frac{\langle\bar{x}, \bar{y}\rangle}{\|\bar{x}\| \bar{y} \|}=\frac{\sum_{i=1}^{n} x_{i} y_{i}}{\sqrt{\sum_{i=1}^{n}\left(x_{i}\right)^{2} \sum_{i=1}^{n}\left(y_{i}\right)^{2}}}
$$

Generally, predictions of the gas temperature inside the corridor show good levels of qualitative agreement with measured values. In more details, it was found that gas temperatures inside the corridor when the burner is located at the back are significantly, as is also depicted in the spatial temperature distribution in Figure 4. In under-ventilated cases with low ventilation factors (e.g. BC30W25H25), FDS under-predicts the temperatures at the vicinity of the burner and the fire plume location is not accurately predicted. Higher ventilation factors result in better agreement both at the front and the rear of the corridor as indicated by the errors in Box A for test cases BC30W50H50 and BC30W50H25 corresponding to the maximum $\varepsilon_{2}$ valued 0.999 and the minimum $\varepsilon_{1}$ valued 0.105 , respectively. EVF are predicted to eject through the opening consistently but temperature profiles in Region III do not remain constant for test cases BC30W30H30, BC30W50H25 and FR30W50H25. In the simulations, the flame plume moves towards the opening more intensively when compared to the experiments, thus resulting in under-prediction of temperatures at the back of the corridor and over-prediction at the vicinity of the opening at Box A. When the burner is positioned near the opening in over-ventilated cases (e.g. FR30W25H25 and FR30W50H50), gas temperatures are substantially under predicted, c.f. Table 3 with $\varepsilon_{2}$ valued 0.987 and 0.961 respectively.

Figure 14 depicts the vertical distribution of the time-averaged (over Region III) heat flux measured using thin steel plate probes $[30,33]$ at the centreline of the façade for all test cases. The effect of burner position on the predicted fire plume shape is evident. In under-ventilated test cases, FR30W30H30, 
FR30W50H25 and BC30W25H25, BC30W50H25, BC30W50H50, a significant portion of combustion takes place outside the corridor. This is due to the inadequate mass air flow rate that cannot sustain complete combustion, thus resulting in unburnt gaseous fuel and smoke exiting the corridor which leads to a more intensified EVF. Both the predicted and measured heat fluxes decrease with increasing height as expected. The highest heat flux is always located along the centreline, except for the test cases where the front of the enclosure is completely open, i.e., BC30W50H50 and FR30W50H50. In these two cases, the EVF emerge as two separate flames. Predicted heat fluxes are lower than measurements in all test cases which is consistent with the results shown in Figures 11 and 12. The discrepancies appear larger for cases where the burner is positioned at the rear of the corridor and cases where the width of the opening equals that of the corridor. It is important to point out that most of the cases examined in this work are ventilation-controlled, for which the predictive ability of FDS is known to be lacking.

\section{CONCLUSIONS}

The dynamic nature of Externally Venting Flames (EVF) requires the use of advanced modelling methodologies, capable of describing the relevant physical phenomena. The commonly used prescriptive methodologies are based on phenomenological approaches that exhibit certain limitations, especially when structures with complex geometry are considered. CFD tools may provide significant assistance to the fire safety engineering analysis of EVF, by offering the opportunity to obtain an in-depth view of the spatial and temporal distribution of important physical parameters such as velocity, gas temperatures, wall temperatures, heat fluxes etc. In the current work, a series of medium-scale fire tests using liquid pool fires were analysed numerically to investigate the effect of fire location and ventilation parameters on the fire development inside the corridor and burning characteristics of EVF. The obtained predictions 
are compared to available experimental data. The main conclusions of this work can be summarized as follows:

1. FDS generally predicts accurately the gas temperature inside the corridor and captures well the detachment and propagation of the flame when the burner is positioned at the back of the corridor, although the main combustion zone is not reproduced accurately. The numerical results also show that after attaining under-ventilated conditions the heat release rate inside the enclosure remains constant having a value of $1110 A_{o} H_{o}{ }^{1 / 2}$ even after EVF emerge through the opening, which confirms the experimental finding in [4] that the amount of air inflow in long corridors is less than that in rectangular enclosures with the same opening dimensions.

2. The heat fluxes on the floor of the corridor are reasonably predicted in terms of both trends and maximum values when the fire is located at the back of corridor. For the test cases where the burner is located at the front of the corridor, the heat fluxes are generally under-predicted, and the location of the predicted peak heat fluxes are also different from that found in the experiments.

3. For the heat flux on the façade, predictions are in better agreement with the experimental data when the fire is located at the front of the corridor because in these cases flames eject almost immediately after ignition and a significant portion of burning occurs externally resulting in much higher heat fluxes. Nonetheless, the predicted heat fluxes are still considerably less than the measurements. The large discrepancies indicate, in addition to possible underprediction of external burning, the burning characteristics of the EVF (such as shape and temperature) may also not be correctly predicted by the model.

4. The present work provides a framework towards understanding the physics of the fire growth in corridor-shaped structures. Future experiments should aim at further investigating the 
effect of corridor geometry (e.g. investigation of different aspect ratios and geometrical configurations) as well as more detailed measurements of the EVF. The predictive ability of the numerical model will be further assessed by using a larger dataset of medium- and fullscale corridor-façade fire configurations in a range of realistic fire scenarios.

\section{REFERENCES}

[1]. I.R. Thomas, I.D. Bennetts, Fires in enclosures with single ventilation openings-comparison of long and wide enclosures, Fire Saf. Sci. Proc. Int. Symp. Int. Assoc. Fire Saf. Sci., 6 (1999), pp. 941-952 https://doi.org/10.3801/IAFSS.FSS.6-941

[2]. S. Miyazaki, Y. Watanabe, Experimental Study on Fire Phenomena of Liquid Fuel in a SmallSized Tunnel--Burning Behavior of N-Heptane, Report of Research Institute of Japan, No. 71, 33-42, March 1991.

[3]. L.H. Hu, R. Huo, W.K. Chow, Studies on buoyancy-driven back-layering flow in tunnel fires Exp. Therm. Fluid Sci., 32 (2008), pp. 1468-1483 https://doi.org/10.1016/j.expthermflusci.2008.03.005 [4]. K. Chotzoglou, E. Asimakopoulou, J. Zhang, M.A. Delichatsios, Experimental investigation of burning behaviour of liquid pool fire in corridor-like enclosure, Fire Safety J. 108 (2019) 102826, https://doi.org/10.1016/j.firesaf.2019.102826

[5]. E. Asimakopoulou, K. Chotzoglou, D. Kolaitis, J. Zhang, M.A. Delichatsios, Numerical investigation of Externally Venting Flame characteristics in a corridor-façade configuration, In: Proceedings of the Ninth International Seminar on Fire and Explosion Hazards (ISFEH9), pp. 459-468, https://doi.org/10.18720/spbpu/2/k19-39 
[6]. E. Yii, C. Fleischmann, A. Buchanan, A., Vent flows in fire compartments with large openings, J. Fire Prot. Eng. 17 (2007) 221-237. https://doi.org/10.1177/1042391507069634

[7]. C.Y. Lin, Study of exposure fire spread between buildings by radiation, Journal of Chinese Institute of Engineering 23 (2000) 493-504. https://doi.org/10.1080/02533839.2000.9670570

[8]. D. Yang, L.H. Hu, Y.Q. Jiang, R. Huo, S. Zhu, X.Y. Zhao, Comparison of FDS predictions by different combustion models with measured data for enclosure fires, Fire Safety J. 45 (2010) 298-313. https://doi.org/10.1016/j.firesaf.2010.06.002

[9]. W. Zhang, A. Hamer, M. Klassen, D. Carpenter, R. Roby, Turbulence statistics in a fire room model by large eddy simulation, Fire Safety J. 37 (2002) 721-752, 2002, https://doi.org/10.1016/S0379$\underline{7112(02) 00030-9}$

[10] Q.T. Nguyen, P. Tran, T.D. Ngo, P.A. Tran, P. Mendis, Experimental and computational investigations on fire resistance of GFRP composite for building façade, Composites Part B: Engineering, 62, 218-229, 2014. https://doi.org/10.1016/j.compositesb.2014.02.010

[11] W. Jahn, G. Rein, J.L. Torero, A posteriori modelling of the growth phase of Dalmarnock Fire Test One, Building and Environment 46, 1065-1073, 2011.

https://doi.org/10.1016/j.buildenv.2010.11.001

[12] P.M. Giraldo, A. Lacasta, J. Avellaneda, C. Burgos, Computer simulation on fire behaviour in the ventilated cavity of ventilated façade systems, MATEC Web of Conferences 9, 03002, 2013. https://doi.org/10.1051/matecconf/20130903002

[13] B.R Martinez., Contribution to the study by numerical simulation of a fire plume coming out through a window on façade: Application to the comprehension of the wind influence on an eventually stack effect, MATEC Web of Conferences, 9, 03004, 2013.

https://doi.org/10.1051/matecconf/20130903004 
[14] Z. Yan, C. Zhao, Y. Liu, X. Deng, X. Ceng, S. Liu, B. Lan, R. Nilsson, S. Jeansson, Experimental study and advanced CFD simulation of fire performance of building external wall insulation system, MATEC Web of Conferences, 9, 03005, 2013. https://doi.org/10.1051/matecconf/20130903005

[15] L. Peng, Z. Ni, X. Huang, Experimental and numerical study of fire spread upon double-skin glass facades, MATEC Web of Conferences, 9, 03002, 2013.

https://doi.org/10.1051/matecconf/20130903009

[16]. J.E. Floyd, Comparison of CFAST and FDS for fire simulation with HDR T51 and T52 tests, National Institute of Standards and Technology, NISTIR 6866, U.S., 2002.

https://doi.org/10.6028/NIST.IR.6866

[17]. H.Y. Wang, Numerical study of under-ventilated fire in medium-scale enclosure, Build. Environ, 44 (2009) 1215-1227. https://doi.org/10.1016/j.buildenv.2008.09.011

[18] J.H. Mammoser, F. Battaglia, A computational study on the use of balconies to reduce flame spread in high-rise apartment fire, Fire Safety J. 39 (2004) 277-296.

https://doi.org/10.1016/j.proeng.2014.04.075

[19] A. Meunders., C. Trettin, F. Wittbecker, The capability of FDS to model flames and plumes emerging from compartment openings, Proceedings of the International Congress of Fire Computer Modelling, 457-470, Santander, Spain, 18-19 October, 2012.

[20] K. Satoh, K. Kuwahara, Numerical study of window-to-window propagation in high-rise building fires, Proceedings of the $3^{\text {rd }}$ International Symposium of Fire Safety Science, 355-364, Edinburg, UK, 8-12 July 1991. https://doi.org/10.3801/IAFSS.FSS.3-355 
[21] E.R. Galea, D. Berhane, N.A. Hoffmann, CFD Analysis of Fire Plumes from windows with external protrusions in high rise buildings, Proceedings of the $6^{\text {th }}$ International INTERFLAM Conference, $307-$ 319, Oxford, UK, 30 March - 1 April, 1993.

[22]. S. Yuan, J. Zhang, Large eddy simulation of compartment fire with solid combustibles, Fire Safety J. 44 (2009) 349-632, 2009. https://doi.org/10.1016/j.firesaf.2008.08.002

[23]. C.A. Empis, Analysis of the compartment fire parameters influencing the heat flux incident on the structural façade, Ph.D. Thesis, University of Edinburgh, U.K., 2010.

[24]. M.J. Hurley, Performance-Based Design, SFPE handbook of fire protection engineering, SFPE, 1233-1261, 2016.

[25]. D.I. Kolaitis, E.K. Asimakopoulou, M.A. Founti, Fire behaviour of gypsum plasterboard wall assemblies: CFD simulation of a full-scale residential building, Case Studies in Fire Safety 7 (2017) 2335. https://doi.org/10.1016/j.csfs.2016.11.001

[26] K. McGrattan, S. Hostikka, R. McDermott, J. Floyd, M. Vanella, Fire Dynamics Simulator User's Guide. NIST Special Publication 1019, Sixth Edition, http://dx.doi.org/10.6028/NIST.SP.1019 [27]. X. Zhang, M. Yang, J. Wang, Y. He, Effects of computational domain on numerical simulation of building fires, J. Fire Prot. Eng. 20 (2010) 225-250. https://doi.org/10.1177/1042391510367349 [28] K. McGrattan, S. Hostikka, R. McDermott, J. Floyd, M. Vanella, Fire Dynamics Simulator Technical Reference Guide, Volume 1: Mathematical Model. NIST Special Publication 1018-1, Sixth Edition, http://dx.doi.org/10.6028/NIST.SP.1018

[29]. Y.P. Lee., M.A. Delichatsios, G. Silcock, Heat fluxes and flame heights in facades from fires in enclosures of varying geometry, Proc. Comb. Inst. 31 (2007) B2521-2528.

https://doi.org/10.1016/j.proci.2006.08.033 
[30]. J. Zhang, M.A. Delichatsios, Determination of the convective heat transfer coefficient in threedimensional inverse heat conduction problems, Fire Safety J. 44 (2009) 681-690. https://doi.org/10.1016/j.firesaf.2009.01.004

[31]. L. Audouin, L. Chandra, J.L. Consalvi, L. Gay, E. Gorza, V. Hohm, S. Hostikka, T. Ito, W. Klein-Hessling, C. Lallemand, T. Magnusson, N. Noterman, J.S. Park, J. Peco, L. Rigollet., S. Suard, P. Van-Hees, Quantifying differences between computational results and measurements in the case of large scale well confined fire scenario, Nuclear Engineering and Design 241 (2011) 18-31. https://doi.org/10.1016/j.nucengdes.2010.10.027 [32]. ASTM E1355-97, Standard guide for evaluating the predictive capability of deterministic fire models, American Society for Testing and Materials International, West Conshohocken, U.S.A, 2006. [33]. Y. Lee, M.A. Delichatsios, G.W.H. Silcock, Heat flux distribution and flame shapes on the inert façade, Fire Safety Science 9 (2008) 193-204. https://doi.org/10.3801/IAFSS.FSS.9-193 
NONMENCLATURE

\begin{tabular}{|c|c|c|}
\hline Symbol & Units & Description \\
\hline$\overline{A_{o}}$ & $\left(\mathrm{~m}^{2}\right)$ & Area of the opening \\
\hline$C$ & $(-)$ & Ventilation coefficient \\
\hline$C_{s}$ & $(-)$ & Smagorinsky constant \\
\hline$D^{*}$ & $(\mathrm{~m})$ & Characteristic fire diameter \\
\hline$H_{o}$ & $(\mathrm{~m})$ & Height of the opening \\
\hline$Q_{\text {exp }}$ & $(\mathrm{kW})$ & Experimentally measured heat release rate \\
\hline$Q_{\text {num, in }}$ & $(\mathrm{kW})$ & Numerical prediction of the heat release rate inside the corridor \\
\hline$Q_{\text {num, out }}$ & $(\mathrm{kW})$ & Numerical prediction of the heat release rate outside the corridor \\
\hline$Q_{\text {num, total }}$ & $(\mathrm{kW})$ & Numerical prediction of the total heat release rate \\
\hline$Q_{t h}$ & $(\mathrm{~kW})$ & Theoretical hear release rate \\
\hline $\mathrm{L}$ & $(\mathrm{m})$ & Path length \\
\hline$P_{r}$ & $(-)$ & Prandtl number \\
\hline$S_{c}$ & $(-)$ & Schmidt number \\
\hline$r_{o}$ & $(-)$ & Oxygen to fuel stoichiometric ratio \\
\hline$t_{d u r}$ & (s) & Experiment duration \\
\hline$t_{E V F}$ & $(-)$ & Time of EVF ejection from the opening \\
\hline $\boldsymbol{u}$ & $(\mathrm{m} / \mathrm{s})$ & Velocity vector \\
\hline$u$ & $(\mathrm{~m} / \mathrm{s})$ & U-component of velocity \\
\hline$v$ & $(\mathrm{~m} / \mathrm{s})$ & V-component of velocity \\
\hline$Y_{O 2, \text { air }}$ & $(-)$ & Mass fraction of oxygen in air \\
\hline
\end{tabular}


$w$

$$
W_{o}
$$

$x$

$y$

$\Delta$

$\delta x$

$\delta t$

$\varepsilon_{1}$

$\varepsilon_{2}$ $(\mathrm{m} / \mathrm{s}) \quad \mathrm{W}$-component of velocity

(m) Width of the opening

(-) Experimental value

(-) Numerical value

(m) One cell width

(m) Nominal size of the grid cell

(s) One-time step

(-) Projection coefficient

(-) Inner product cosine

\begin{tabular}{ll}
\hline Acronyms & \\
\hline CFD & Computational Fluid Dynamics \\
EVF & Courant-Friedrich-Levy \\
FDS & Externally Venting Flames \\
GER & Flobal Equivalence Ratio \\
HRR & Heat release rate \\
HRRPUA & Heat Release Rate per Unit Area \\
MLR & Mass loss rate \\
O & Over ventilated \\
U & Under ventilated \\
VLES & Very Large Eddy Simulation \\
\hline
\end{tabular}




\section{FIGURE CAPTIONS}

Fig. 1: Schematic of the experimental facility, units displayed are in $\mathrm{cm}$.

Fig. 2: Temporal evolution of experimentally measured HRR and CO concentration in the hood for test cases BC30W25H25 (a), BC30W30H30 (b), BC30W50H25 (c), BC30W50H50 (d), FR30W25H25 (e), FR30W30H30 (f), FR30W50H25 (g) and FR30W50H50 (h).

Fig. 3. Simulation setup for test cases BC30W30H30 (left) and FR30W30H30 (right).

Fig. 4. Temperature-dependent values of heat capacity and thermal conductivity for the fibreboards used in the compartment's walls.

Fig. 5. Experimental (a-d) and numerical (e-h) spatial distribution of the gaseous temperature at the corridor interior for test case BC30H30W30 at $60 \mathrm{~s}(\mathrm{a})$ and (e), $120 \mathrm{~s} \mathrm{(b)}$ and (f), $400 \mathrm{~s} \mathrm{(c)} \mathrm{and} \mathrm{(g)} \mathrm{and}$ $900 \mathrm{~s}(\mathrm{~d})$ and $(\mathrm{h})$.

Fig. 6. Temporal evolution of the HRR experimentally measured in the hood $(Q$ exp $)$ and the numerical predictions of the HRR inside the corridor $\left(Q_{\text {num,in }}\right)$, outside $\left(Q_{\text {num,out }}\right)$ and total HRR $\left(Q_{\text {num,total }}\right)$ for test case $\mathrm{BC} 30 \mathrm{H} 30 \mathrm{~W} 30$. 
Fig. 7. Experimental (a-d) and numerical (e-h) spatial distribution of the gaseous temperature at the corridor interior for test case FR30H30W30 at $60 \mathrm{~s}$ (a) and (e), $120 \mathrm{~s} \mathrm{(b)} \mathrm{and} \mathrm{(f),} 400 \mathrm{~s} \mathrm{(c)} \mathrm{and} \mathrm{(g)} \mathrm{and}$ $900 \mathrm{~s}(\mathrm{~d})$ and (h).

Fig. 8. Temporal evolution of the HRR experimentally measured in the hood $\left(Q_{\text {exp }}\right)$ and the numerical predictions of the HRR inside the corridor $\left(Q_{\text {num,in }}\right)$, outside $\left(Q_{\text {num,out }}\right)$ and total HRR $\left(Q_{\text {num,total }}\right)$ for test case FR30H30W30.

Fig. 9. Experimental and numerical values of averaged heat flux values in the corridor floor over the steady state period against the distance from the opening for cases where the fuel pan is located at the front of the corridor.

Fig. 10. Experimental and numerical values of averaged heat flux values in the corridor floor over the steady state period against the distance from the opening for cases where the fuel pan is located at the back of the corridor.

Fig. 11. Predictions and measurements of the temporal evolution heat fluxes for test case BC30W30H30.

Fig. 12. Predictions and measurements of the temporal evolution heat fluxes for test case FR30W30H30.

Fig. 13. Experimental and numerical temporal evolution of the gas temperature at a height of $48 \mathrm{~cm}$ inside the corridor in Boxes A, E and E for test cases FR30W25H25 (a), FR30W30H30 (b), 
FR30W50H25 (c), FR30W50H50 (d), BC30W25H25 (e), BC30W30H30 (f), BC30W50H25 (g) and BC30W50H50 (h).

Fig. 14. Vertical distribution of time-averaged heat flux at the centreline of the façade for the BC (left) and FR (right) test cases. 


\section{TABLE CAPTIONS}

Table 1. CFD numerical studies on medium scale enclosure fires with a single opening.

Table 2. Summary of main operational parameters for the examined test cases.

Table 3. Errors $\varepsilon_{1}$ and $\varepsilon_{2}$ for Boxes $\mathrm{A}$ and $\mathrm{E}$ for all simulated test cases. 
Table 2. Summary of main operational parameters for the examined test cases.

\begin{tabular}{|c|c|c|c|c|c|c|c|c|c|c|}
\hline Test cases & $\begin{array}{c}\text { Burner } \\
\text { position }\end{array}$ & $\begin{array}{c}A_{o} H_{o}{ }^{1 / 2} \\
{\left[\mathrm{~m}^{5 / 2}\right]}\end{array}$ & $\begin{array}{c}1110 A_{o} H_{o}{ }^{1 / 2} \\
{[\mathrm{~kW}]}\end{array}$ & $\begin{array}{c}1500 A_{o} H_{o}^{1 / 2} \\
{[\mathrm{~kW}]}\end{array}$ & $\begin{array}{r}\text { MLR } \\
{[\mathrm{g} / \mathrm{s}]}\end{array}$ & $\begin{array}{c}? ? ? \mathrm{~h} \\
{[\mathrm{~kW}]}\end{array}$ & $\begin{array}{c}\text { GER } \\
{[-]}\end{array}$ & Regime & $\begin{array}{l}t_{\text {dur }} \\
{[\mathrm{s}]}\end{array}$ & $\begin{array}{c}t_{E V F} \\
{[\mathrm{~s}]}\end{array}$ \\
\hline FR30W25H25 & \multirow{4}{*}{ BOX A } & 0.03125 & 34.4 & 46.5 & 1.59 & 42.7 & 0.91 & $\mathrm{O}$ & 1296 & 120 \\
\hline FR30W30H30 & & 0.04929 & 54.2 & 73.5 & 2.81 & 75.3 & 1.02 & $\mathrm{U}$ & 1200 & 60 \\
\hline FR30W50H25 & & 0.06250 & 68.8 & 93.8 & 3.81 & 102.0 & 1.09 & $\mathrm{U}$ & 1282 & 60 \\
\hline FR30W50H50 & & 0.17678 & 194.5 & 265.1 & 3.4 & 91.1 & 0.34 & $\mathrm{O}$ & 1869 & 720 \\
\hline BC30W25H 25 & \multirow{4}{*}{ BOX F } & 0.03125 & 34.4 & 46.9 & 2.41 & 64.5 & 1.38 & $\mathrm{U}$ & 1815 & 1320 \\
\hline BC30W30H30 & & 0.04929 & 54.2 & 73.9 & 4.13 & 110.6 & 1.50 & $\mathrm{U}$ & 1100 & 510 \\
\hline BC30W50H25 & & 0.06250 & 68.8 & 93.8 & 4.5 & 120.5 & 1.29 & $\mathrm{U}$ & 1128 & 300 \\
\hline BC30W50H50 & & 0.17678 & 194.5 & 265.1 & 5.6 & 150.0 & 0.57 & $\mathrm{O}$ & 1008 & 210 \\
\hline
\end{tabular}


Table 1. CFD numerical studies on medium scale enclosure fires with a single opening.

\begin{tabular}{|c|c|c|c|c|}
\hline Ref. & Short description & $\begin{array}{l}\text { FDS } \\
\text { Version }\end{array}$ & Fuel & $\begin{array}{l}\text { Predictions and comparison } \\
\text { with exp. data }\end{array}$ \\
\hline [7] & $\begin{array}{l}\text { Study of the turbulence structure } \\
\text { of the flow and temperature field } \\
\text { in an } 1 / 2 \text { ISO room fire }\end{array}$ & 2 & Heat source & $\begin{array}{l}\text { Mean velocity and interior } \\
\text { gas temperature, intensity of } \\
\text { velocity and temperature } \\
\text { fluctuations, turbulence heat } \\
\text { flux and Reynolds stresses }\end{array}$ \\
\hline [14] & $\begin{array}{l}\text { Assessment of mixture fraction } \\
\text { combustion and radiation models } \\
\text { in an } 2 / 5 \text { ISO room fire }\end{array}$ & 1 and 2 & Natural gas & $\begin{array}{l}\text { Interior gas temperature, } \\
\text { velocity and temperature at } \\
\text { the doorway }\end{array}$ \\
\hline$[20]$ & $\begin{array}{l}\text { Fire spread in a compartment } \\
\text { fire with solid combustibles }\end{array}$ & 4 & $\begin{array}{l}\text { Polyurethane } \\
\text { foam }\end{array}$ & $\begin{array}{l}\text { HRR, compartment } \\
\text { temperature and } \\
\text { properties }\end{array}$ \\
\hline$[15]$ & $\begin{array}{l}\text { Study of under-ventilated } 1 / 3 \\
\text { ISO compartment fire to } \\
\text { investigate EVF occurrence }\end{array}$ & 5 & $\begin{array}{l}\text { Propane and } \\
\text { methane }\end{array}$ & $\begin{array}{l}\text { Interior gas temperature, } \\
\text { transverse velocity, vertical } \\
\text { velocity fluctuation, soot and } \\
\text { CO production, flame } \\
\text { behaviour and heat fluxes }\end{array}$ \\
\hline [6] & $\begin{array}{lcr}\begin{array}{l}\text { Assessment } \\
\text { combustion }\end{array} \text { models } & \text { different } \\
\text { various GER in a } 1 / 2 \text { ISO room }\end{array}$ & 4 and 5 & $\begin{array}{l}\text { Propane and } \\
\text { natural gas }\end{array}$ & $\begin{array}{l}\text { HRR, upper-layer room } \\
\text { temperature and CO yield }\end{array}$ \\
\hline $\begin{array}{l}\text { Current } \\
\text { study }\end{array}$ & $\begin{array}{l}\text { Investigation of } \\
\text { characteristics in a corridor- } \\
\text { façade configuration }\end{array}$ & 6.7 & Ethanol & $\begin{array}{l}\text { See section: } \\
\text { Results and Discussion }\end{array}$ \\
\hline
\end{tabular}


Table 3. Errors $\varepsilon_{1}$ and $\varepsilon_{2}$ for Boxes $\mathrm{A}$ and $\mathrm{E}$ for all simulated test cases.

\begin{tabular}{|c|c|c|c|c|}
\hline \multirow{2}{*}{ Test cases } & \multicolumn{2}{|c|}{ Box A } & \multicolumn{2}{c|}{ Box E } \\
\cline { 2 - 5 } & $\boldsymbol{\varepsilon}_{\boldsymbol{1}}$ & $\boldsymbol{\varepsilon}_{\boldsymbol{2}}$ & $\boldsymbol{\varepsilon}_{\boldsymbol{1}}$ & $\boldsymbol{\varepsilon}_{\boldsymbol{2}}$ \\
\hline FR30W25H25 & 0.188 & 0.987 & $\mathbf{0 . 1 8 7}$ & $\mathbf{0 . 9 9 6}$ \\
\hline FR30W30H30 & 0.134 & 0.992 & 0.318 & $\mathbf{0 . 9 9 6}$ \\
\hline FR30W50H25 & 0.245 & $\mathbf{0 . 9 9 6}$ & 0.245 & $\mathbf{0 . 9 9 6}$ \\
\hline FR30W50H50 & $\mathbf{0 . 1 1 9}$ & 0.961 & 0.850 & 0.965 \\
\hline BC30W25H25 & 0.136 & 0.995 & $\mathbf{0 . 2 5 0}$ & 0.981 \\
\hline BC30W30H30 & 0.355 & 0.936 & 0.739 & 0.935 \\
\hline BC30W50H25 & $\mathbf{0 . 1 0 5}$ & 0.996 & 0.790 & $\mathbf{0 . 9 8 5}$ \\
\hline BC30W50H50 & 0.170 & $\mathbf{0 . 9 9 9}$ & 0.439 & 0.922 \\
\hline
\end{tabular}


FUEL SIDE VIEW

SUPPLY SYSTEM

- Thermocouples
- Steel Plate Heat Flux Meters

- Gardon Gauges

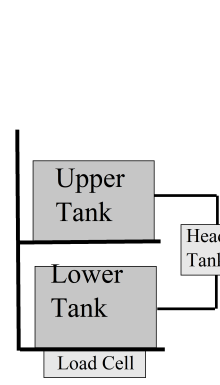

300

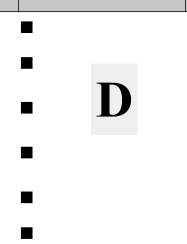

FRONT VIEW

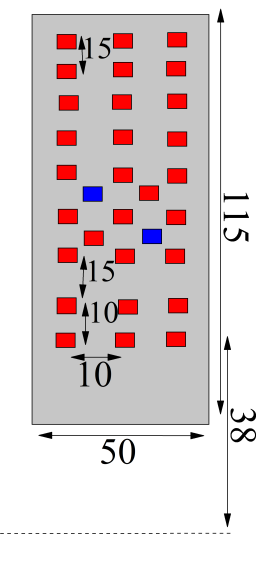




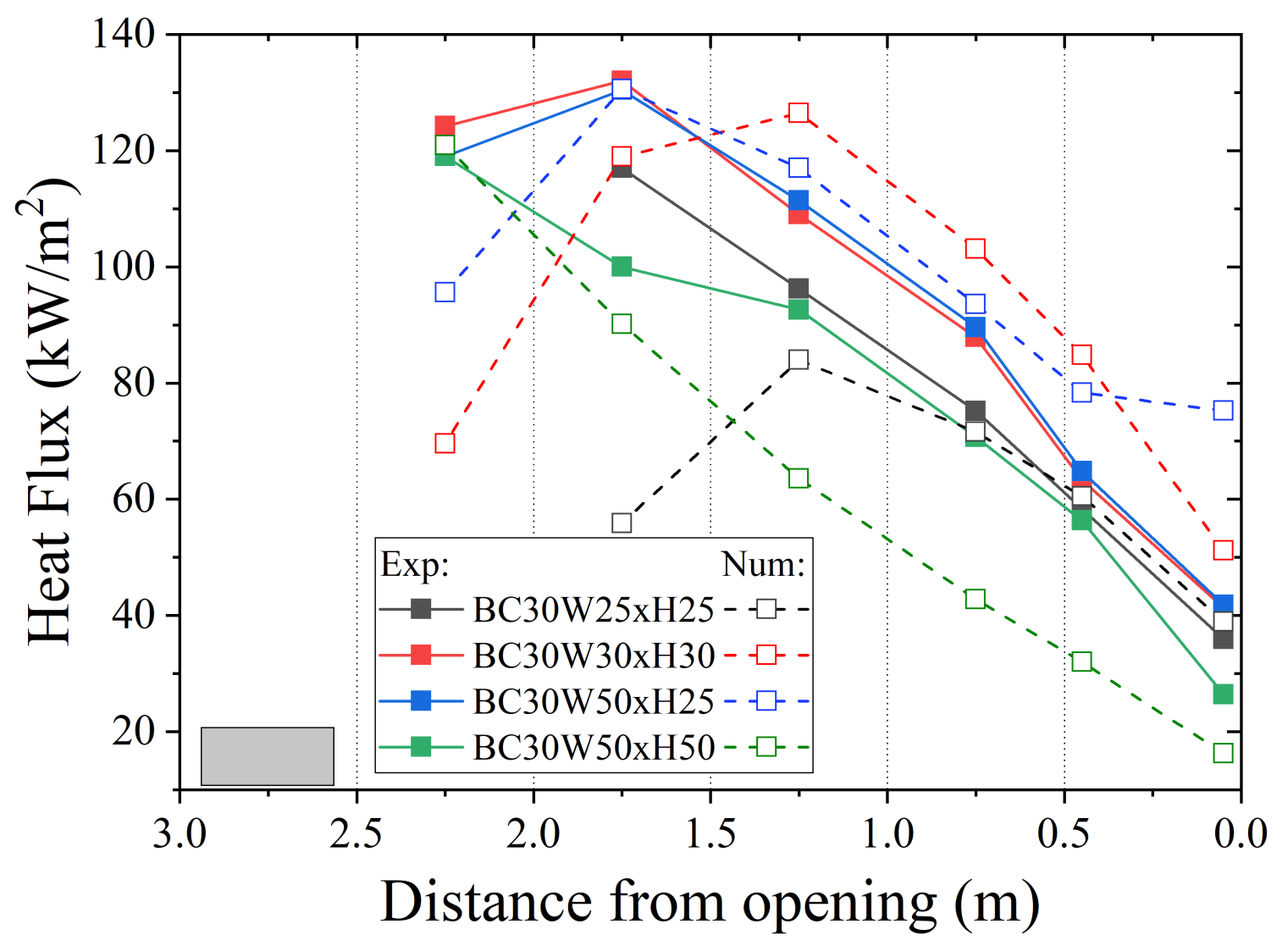




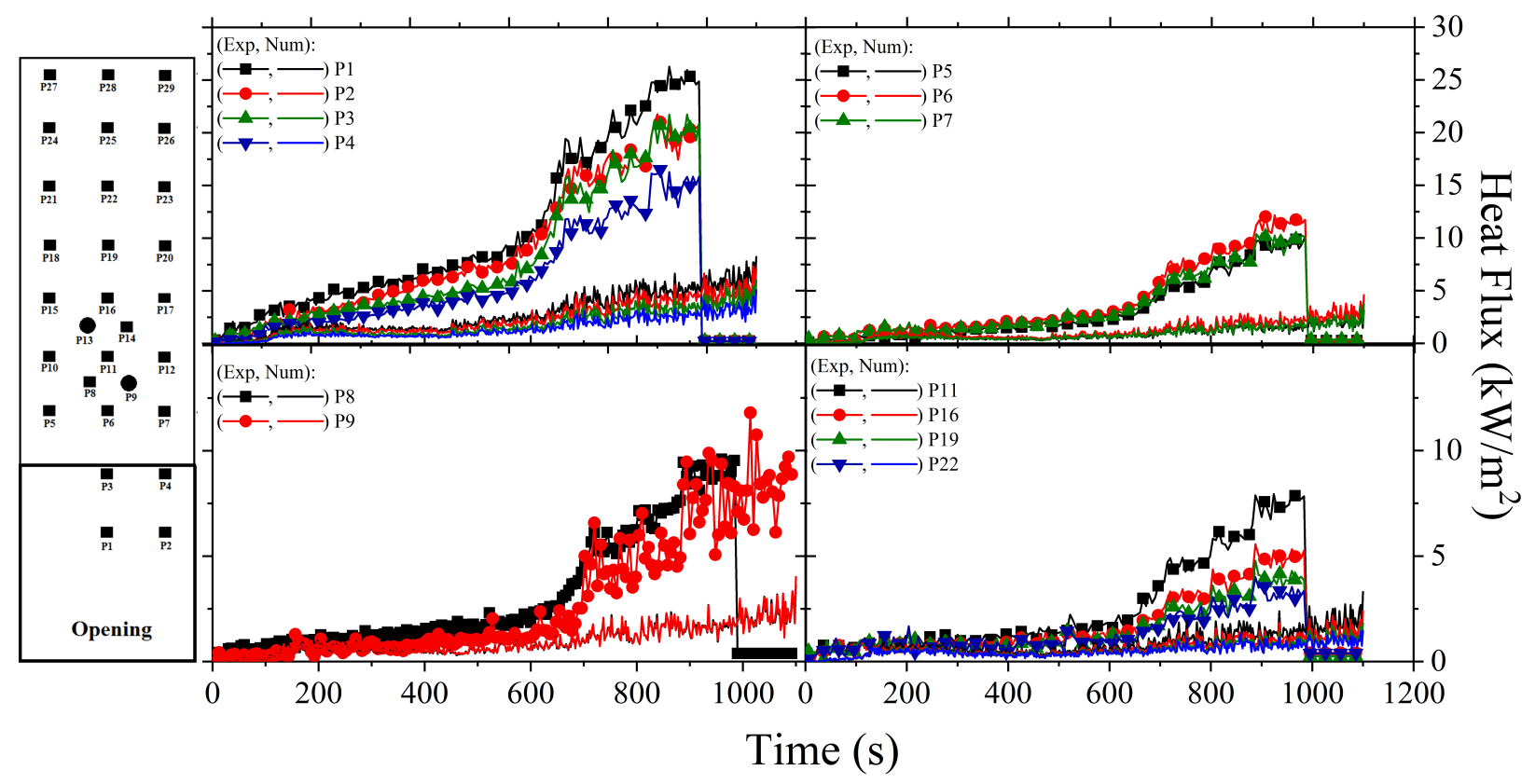




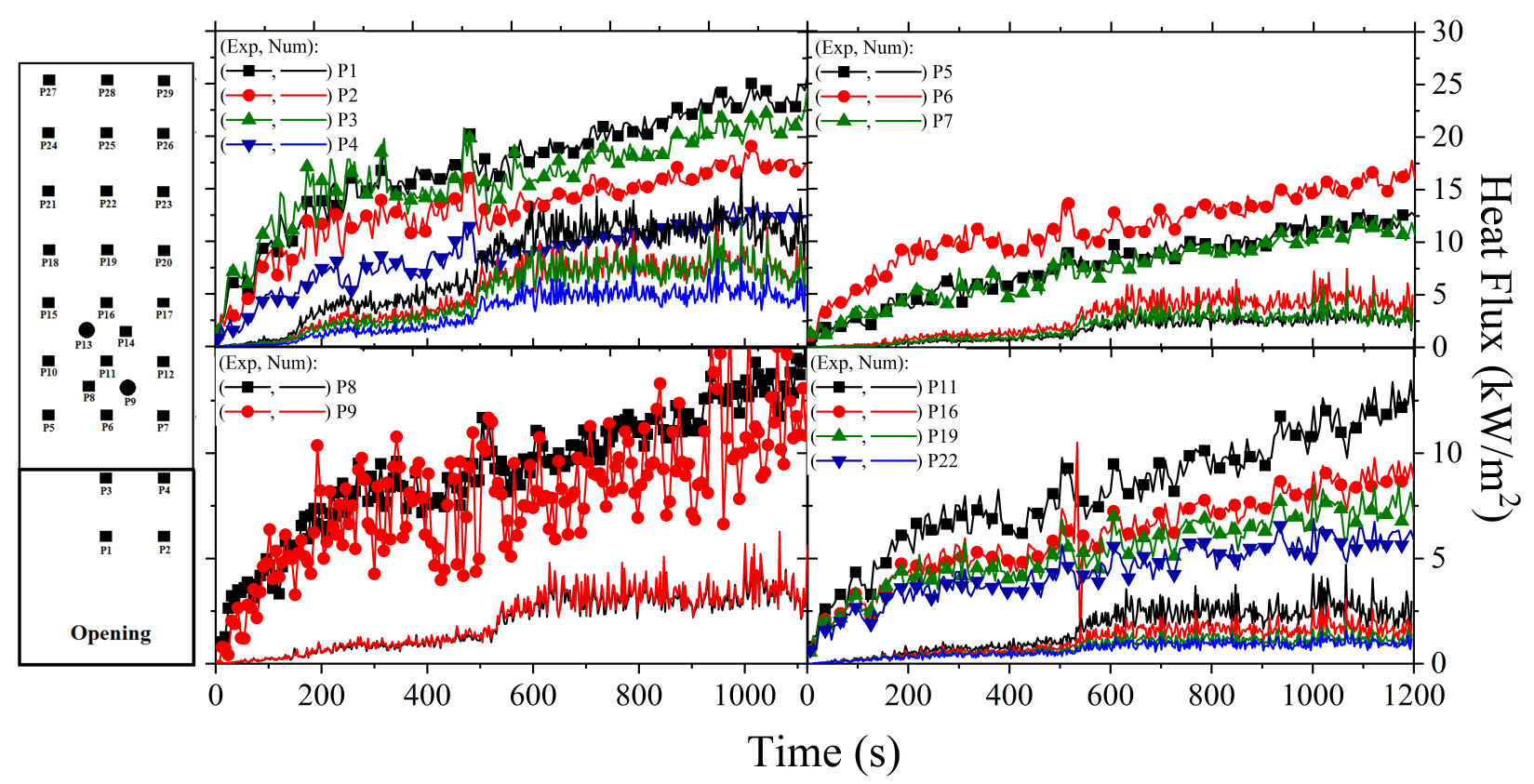




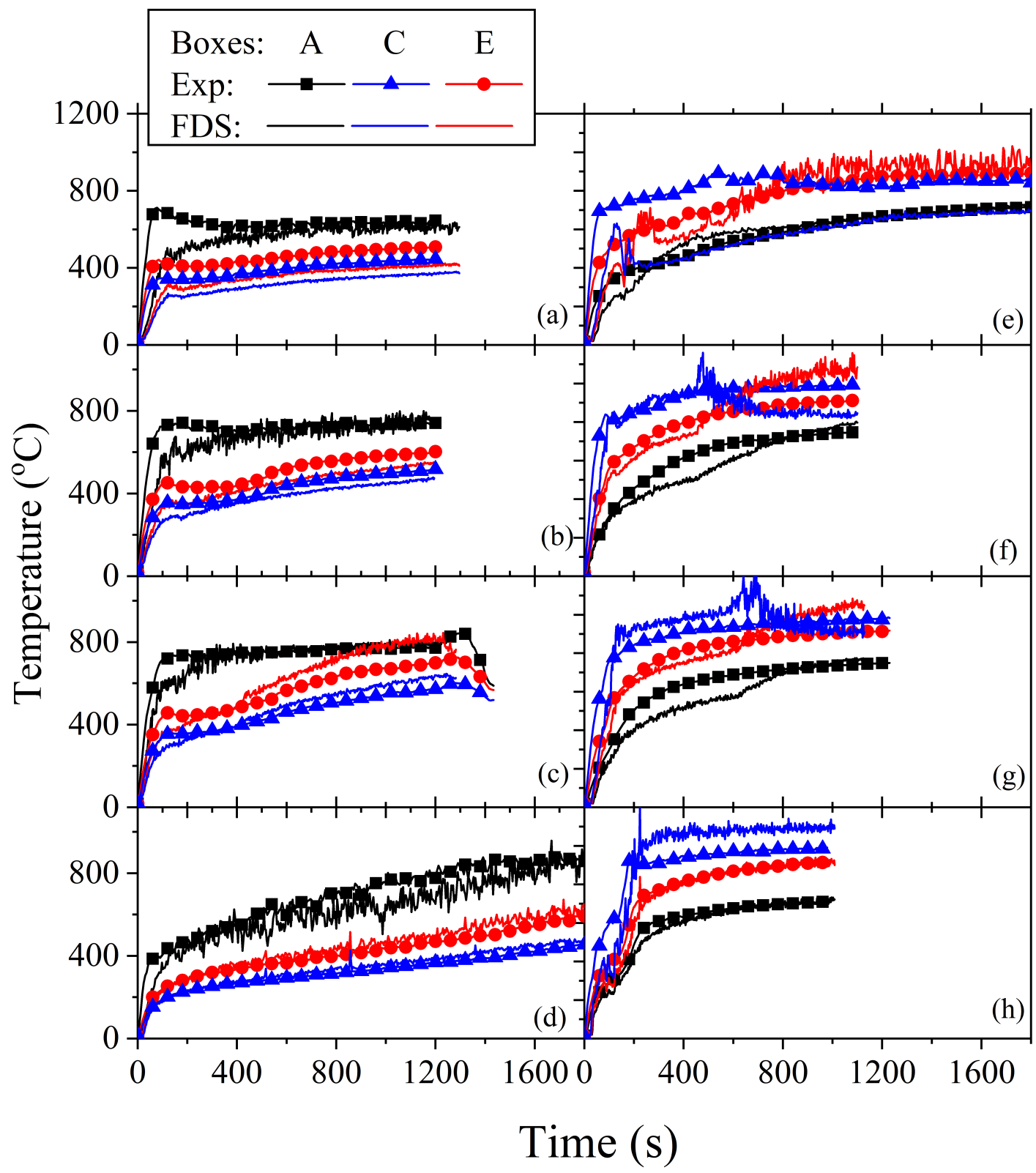




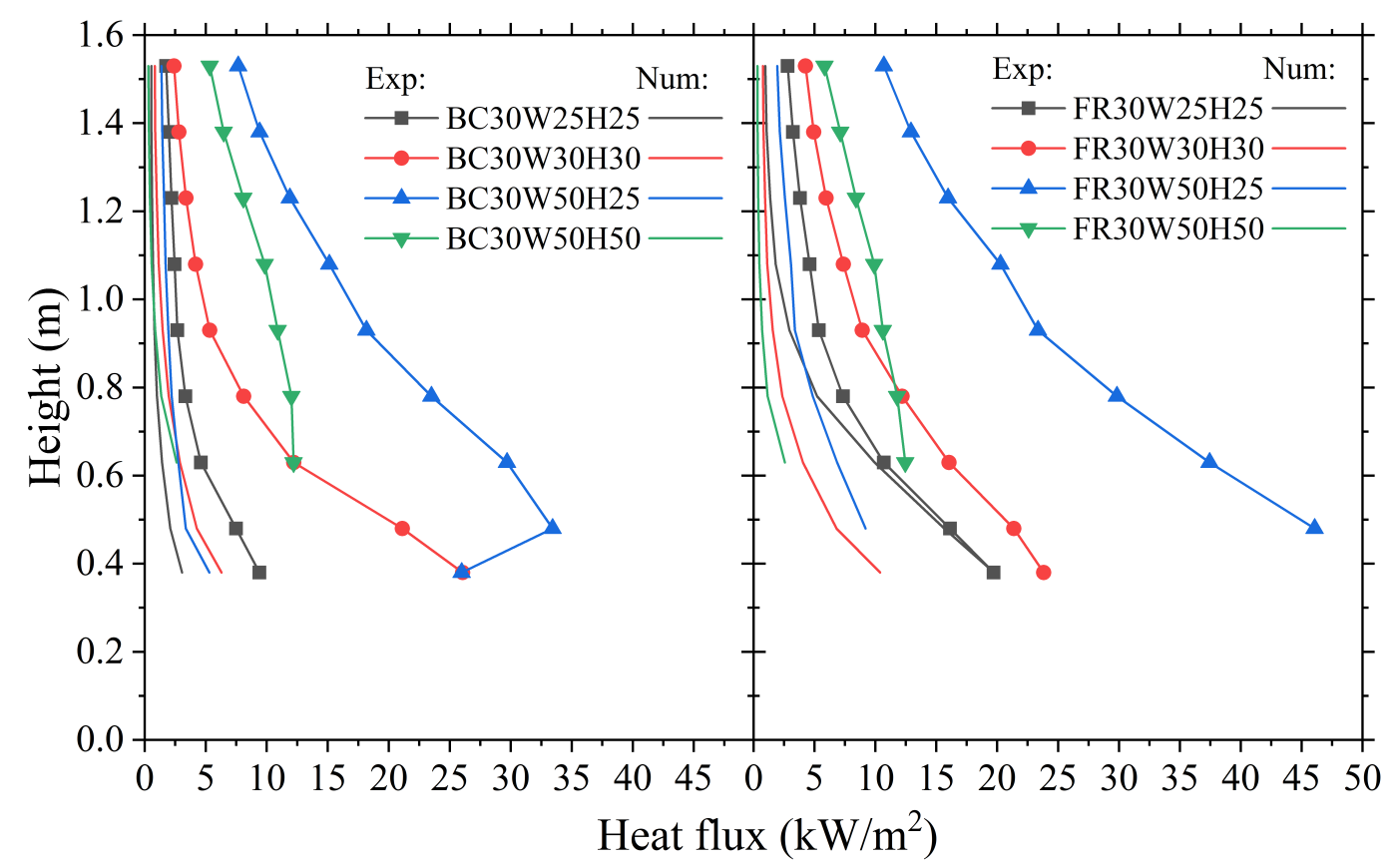




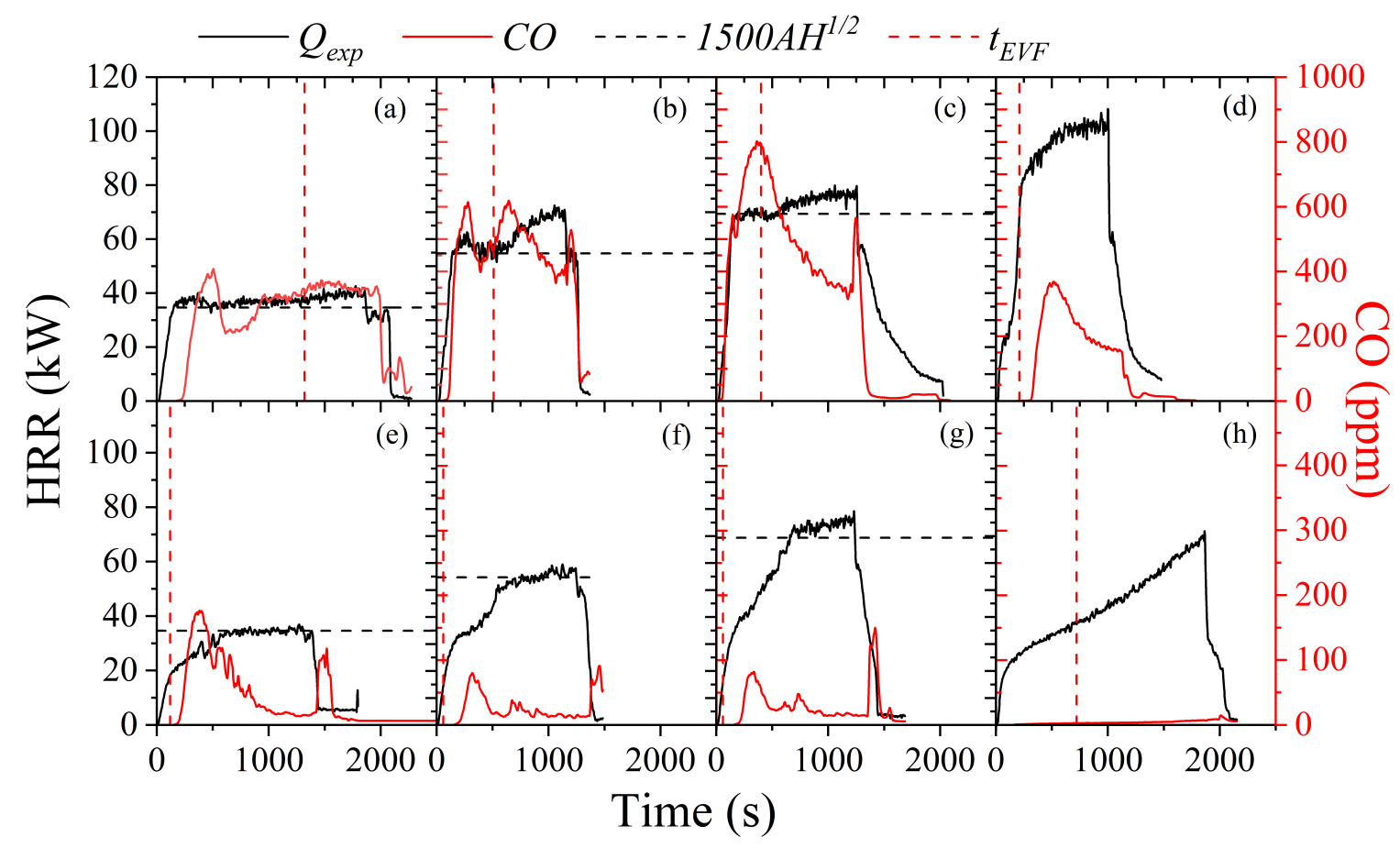




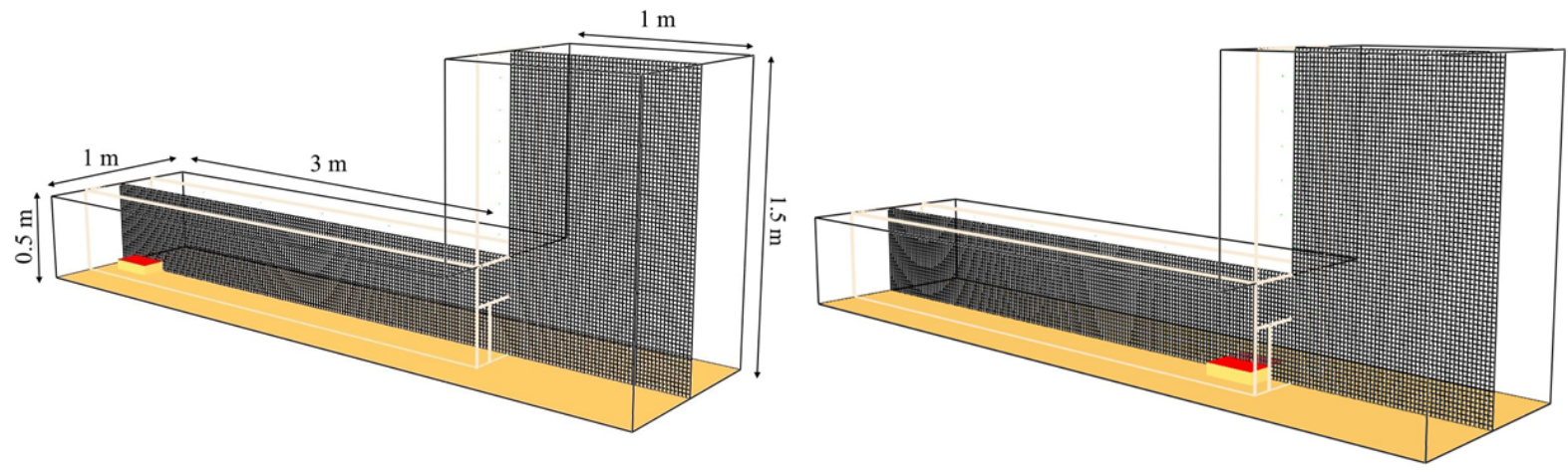




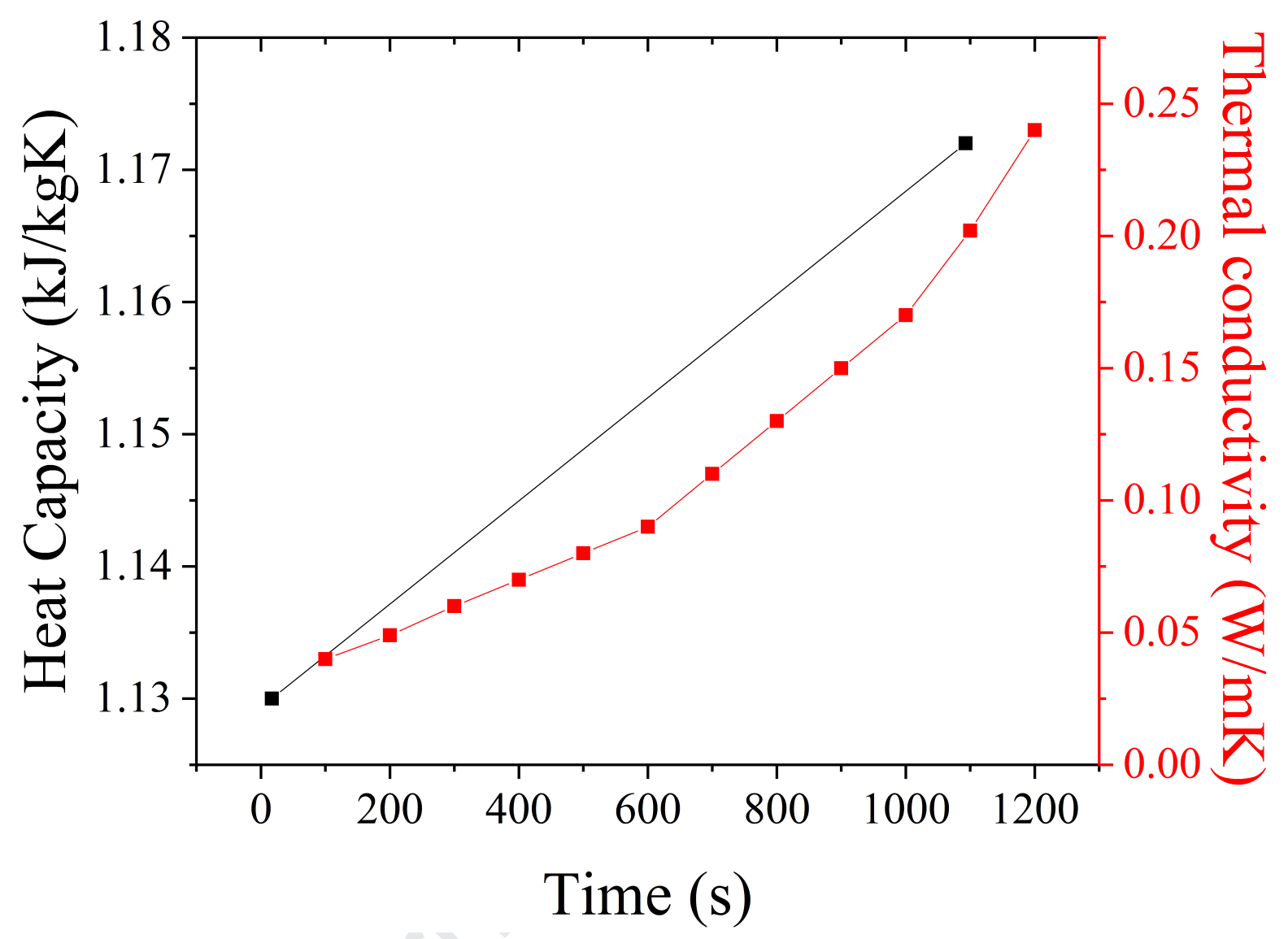


BC30W30H30

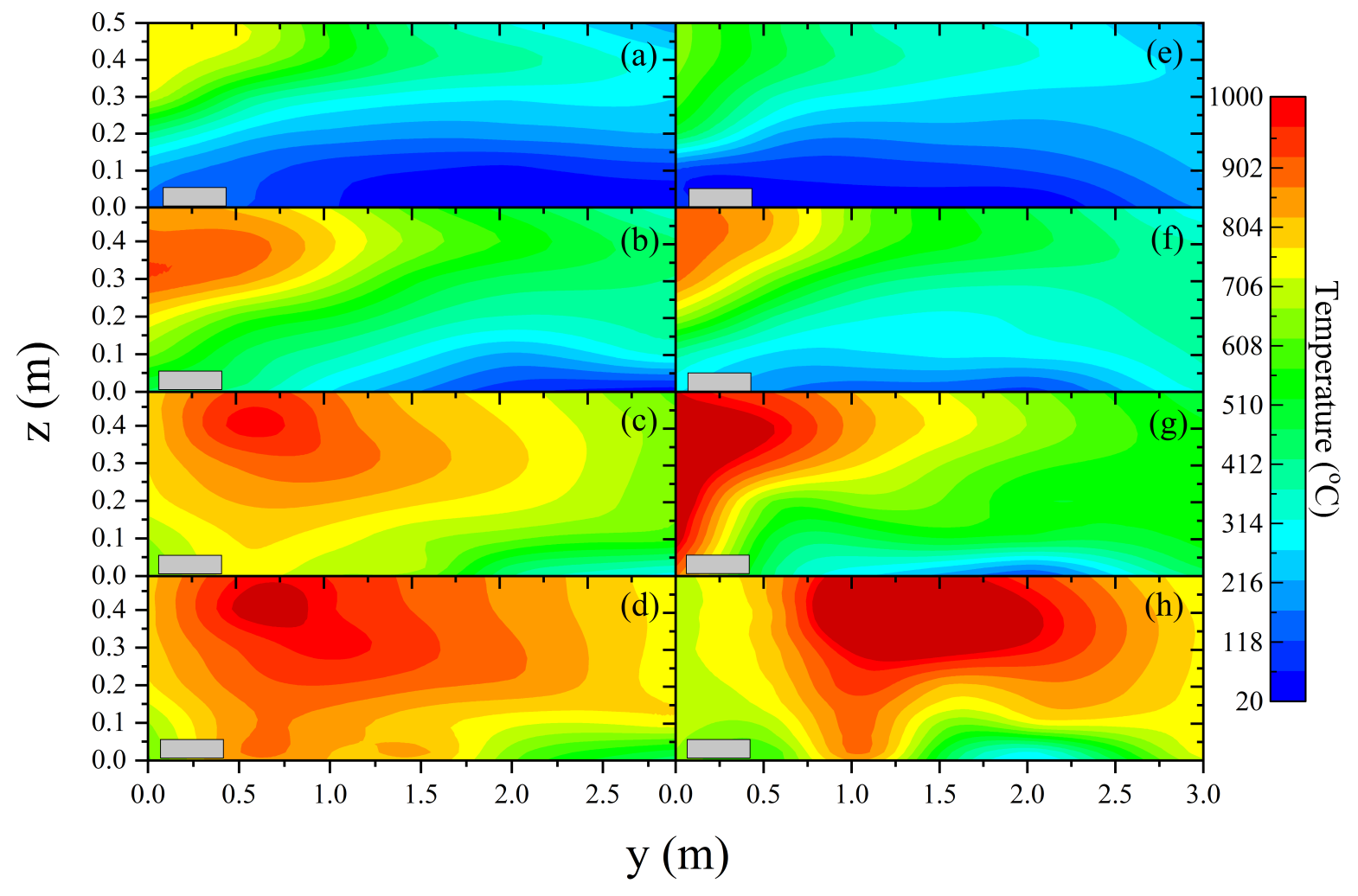




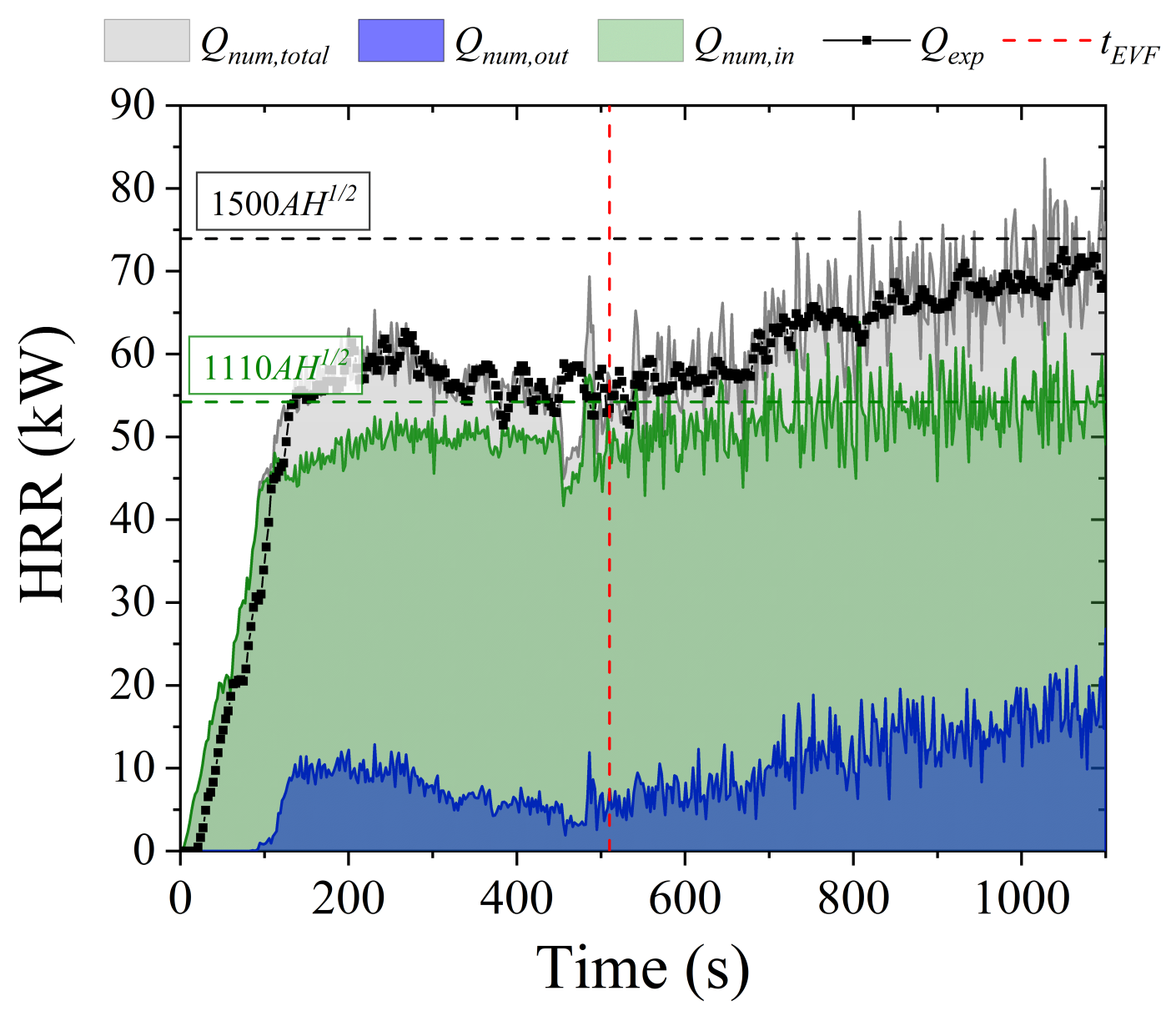




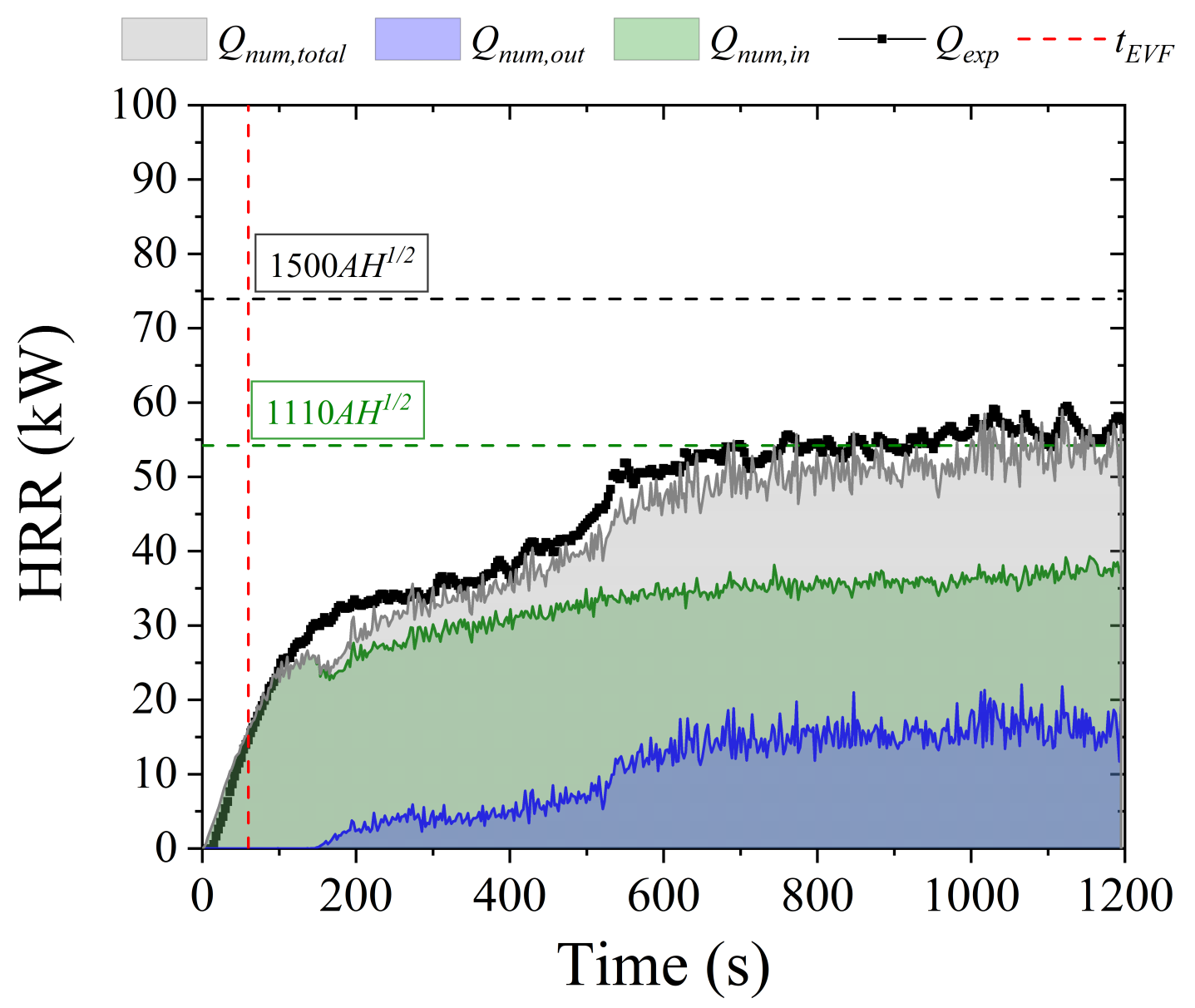




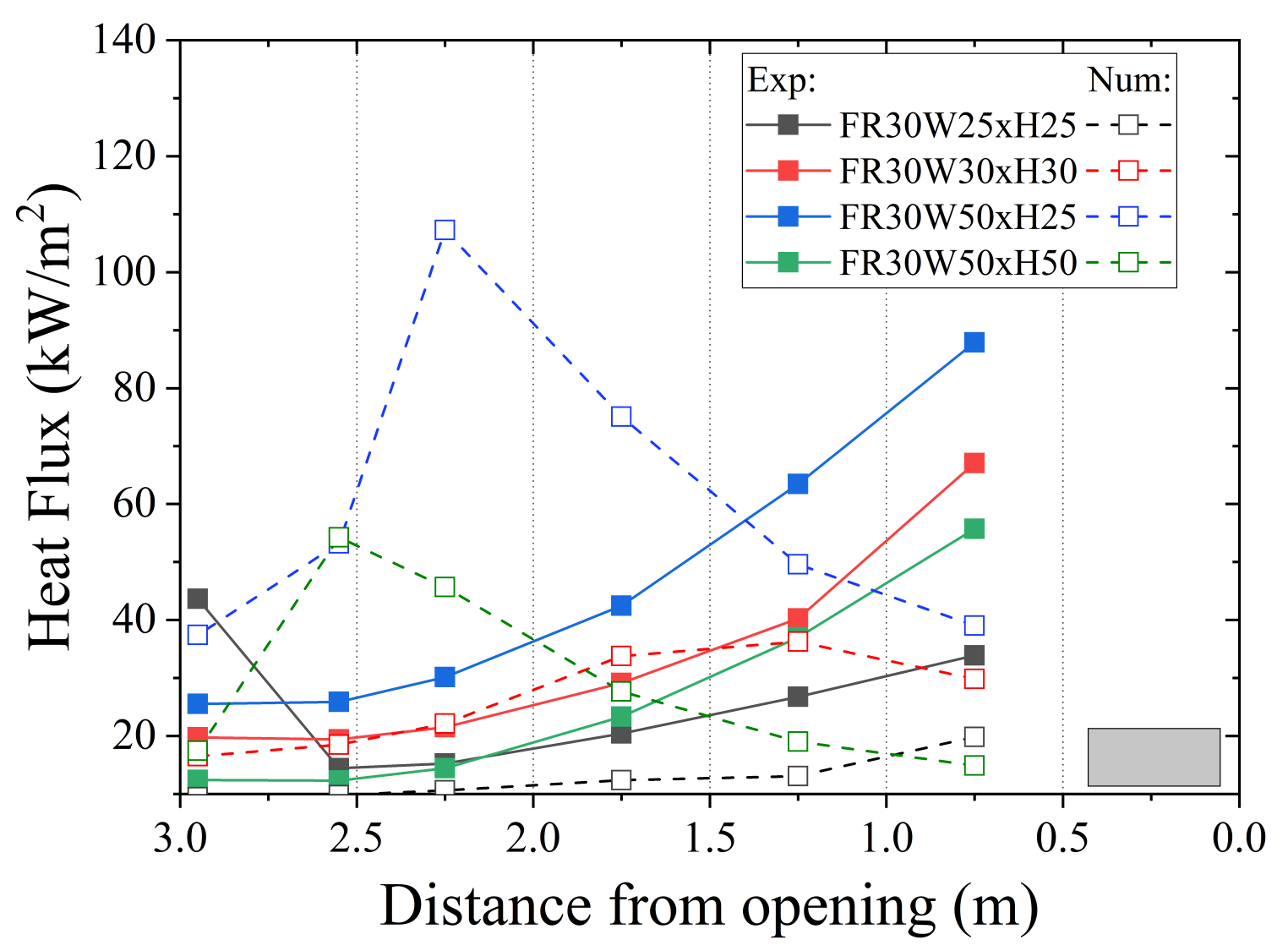


Declarations of interest: none 